\title{
The influence of central corneal thickness on progression of normotensive glaucoma
}

\author{
Elena Nutterova ${ }^{a}$, Klara Maresova ${ }^{b}$, Jan Lestak ${ }^{\mathrm{a}}$
}

\begin{abstract}
Objectives. To verify whether there is a relation between central corneal thickness (CCT) and progression of normotensive glaucoma (NTG), to assess the impact of early changes in the visual field on their progression in time.

Methods and Patients. The sample consisted of two groups of patients with NTG. In the first group there were 50 eyes of 25 persons ( 15 females and 10 males) average age 63 years who had been treated with prostaglandins. The second group consisted of 50 eyes of 25 persons ( 16 females and 9 males) average age of 62 years who had had no local therapy. All patients were cardiologically compensated and had no other internal or neurological disease. Visual acuity was 1.0 with a possible correction (less than \pm 3 dioptres) in all patients. The IOP ranged between $10-15 \mathrm{mmHg}$ in all patients. If hypotensive ophthalmological therapy was initiated, it had been stable for the last five years. In all patients, we monitored CCT, excavation in the papilla (c/d), pattern defect (PD) and overall defect (OD) of the visual field. In 2013, changes in the visual fields were approximately the same in all patients. We compared the results of the visual fields after five years, i.e. the results were obtained in 2018. CCT was measured, using the ultrasound pachymeter Tomey SP-100. PD and OD of the visual field using the glaucoma fast threshold program with the MEDMONT M 700 device. For statistical comparison, we used the paired $t$ test and correlation analysis.

Results. In both groups, we found progression of PD in time ( $P=0.0000, P=0.0001$, respectively). In the patients treated with prostaglandins, $\mathrm{OD}$ had not statistically significantly changed $(P=0.49)$ in contrast to the untreated patients $(P=0.001)$. There was no statistically significant relation between CCT and PD in any of the groups. It was similar between the CCT and OD. In the treated NTG patients, we found a weak correlation between the changes in PD in time $(\mathrm{r}=0.2846, P=0.0438)$ and moderately strong relation for $\mathrm{OD}(\mathrm{r}=-0.63)$. The finding was similar in untreated patients PD $(\mathrm{r}=-0.2, P=0.162)$ and $\mathrm{OD}(\mathrm{r}=-0.443, P=0.001)$.

Conclusion. We found no relationship between progression of changes in the visual fields in CCT. Progression of changes in the visual fields was higher in patients who had more advanced changes at the beginning of observation. The untreated patients had progression of changes in the visual fields both in PD and OD in contrast to those who were taking prostaglandins and presented changes only in PD.
\end{abstract}

Key words: normotensive glaucoma, central corneal thickness, visual field, pattern defect, overall defect

Received: October 14, 2019; Revised: November 7, 2019; Accepted: November 7, 2019; Available online: November 18, 2019 https://doi.org/10.5507/bp.2019.057

(c) 2021 The Authors; https://creativecommons.org/licenses/by/4.0/

${ }^{a}$ Eye Clinic JL FBMI CTU Prague, Czech Republic

${ }^{b}$ Department of Ophthalmology, Faculty of Medicine, Palacky University Olomouc, Czech Republic

Corresponding author: Jan Lestak, e-mail: lestak@seznam.cz

\section{INTRODUCTION}

Normotensive glaucoma (NTG) is defined as progressive optic neuropathy with glaucomatous disc of the optic nerve and visual field in which IOP is equal to or lower than $21 \mathrm{mmHg}$ (ref. ${ }^{1}$ ).

Differences compared to hypertensive glaucoma (HTG) were described in the previous paper ${ }^{2}$. In 2013, we referred to the effects of pharmacological therapy on the progression of changes in the visual fields in HTG. We found no differences between therapy with prostaglandins and beta blockers ${ }^{3}$. We found significant differences in the visual fields in time in NTG. The untreated patients or those treated with local prostaglandins had statistically significant changes in the perimeter compared to those who were treated with beta-blockers. Therefore, the patients with NTG treated with beta-blockers were excluded ${ }^{4}$.

In another study on HTG, we found a correlation of progression of visual field changes with central corneal thickness (CCT) and the fact that progression was greater in patients who had greater changes at baseline . $^{5}$

As for the CCT alone there was no statistically significant difference between patients with HTG and NTG (ref. ${ }^{6}$ ).

Since NTG is pathophysiologically a different disease than HTG, we wondered whether there is a similar relationship between CCT and progression of changes in visual fields over time and in NTG. This was the aim of our study. 


\section{Group and methodology}

Therefore, we included two groups of patients with NTG of approximately the same age in our group (0.58). First group consisted of 50 eyes of 25 persons ( 15 females and 10 males) of average age of 63 years who have been treated with prostaglandins. The second group consisted of 50 eyes of 25 persons ( 16 females and 9 males) of average age of 62 years who have had no local therapy. All patients were cardiologically compensated and had no other internal or neurological disease.

Visual acuity was 1.0 with a possible correction (less than \pm 3 dioptres) in all patients. The IOP ranged between $10-15 \mathrm{mmHg}$ in all patients. If hypotensive ophthalmological therapy was initiated, it had been stable for the last five years. In all patients, we monitored CCT, excavation in the papilla (c/d), pattern defect (PD) and overall defect (OD) of the visual field. In 2013, changes in the visual fields were approximately the same in all patients. We compared the results of the visual fields after five years, i.e. the results were found in 2018. Diagnosis of NTG was confirmed also using electrophysiological examination (pattern electroretinogram and pattern visual evoked potential).

CCT was measured, using the ultrasound pachymeter Tomey SP-100. PD and OD of the visual field using the glaucoma fast threshold program with the MEDMONT M 700 device. For statistical consideration, we used the paired $\mathrm{t}$ test and correlation analysis.

\section{RESULTS}

The observed values and the results are shown in the Table 1 and 2.

Table 1. The observed values in patients treated with prostaglandins.

\begin{tabular}{lc}
\hline Patients treated with prostaglandins & \\
\hline Number of patients & 25 \\
Mean age & $63.16 \pm 0.4$ \\
Lowest & 36 \\
Highest & 76 \\
Mean PD (2013) & $2.85 \pm 1.9$ \\
Mean PD (2018: & $3.79 \pm 2.6$ \\
$P$ & 0.0000 \\
Mean OD (2013) & $2.66 \pm 1.66$ \\
Mean OD (2018: & $2.79 \pm 1.3$ \\
$P$ & 0.49 \\
Dependence between CCT & $\mathrm{r}=-0.205 \quad P=0.154$ \\
$\quad$ and progression of PD & $\mathrm{r}=0.0412 \quad P=0.7765$ \\
Dependence between CCT & $\mathrm{r}=0.2846 \quad P=0.0438$ \\
$\quad$ and progression of OD & $\mathrm{r}=-0.63 \quad P=0.000$ \\
Dependence between PD 2013 & \\
$\quad$ and 2018 & \\
Dependence between OD 2013 & \\
$\quad$ and 2018 &
\end{tabular}

\section{DISCUSSION}

Zeiter et al. and Araie et al. compared changes in visual fields in NTG and HTG and came to the conclusion that the changes were different in both groups. Changes in patients with NTG were predominantly localised closer to the centre ${ }^{7,8}$.

Caprioli and Spaeth showed that scotomas in NTG had a steeper slope, were significantly closer to fixation compared to HTG and exhibited greater depth ${ }^{9}$.

Thonginnetra et al. evaluated NTG and HTG patients using functional and structural tests and found functional differences between these two groups. The results had clinical implications for the evaluation of visual field defects in NTG and HTG eyes. Because a higher prevalence of visual field defects in the central region was found, they recommended that intensive testing of the central 10-degrees of the visual field (10-2 strategy) should be performed on patients with NTG (ref. ${ }^{10}$ ).

These conclusions have been confirmed also in our previous study in which the analysis showed that PD is statistically higher than OD $(P=0.0001)$ in patients with NTG. On the contrary, the patients with HTG had statistically higher values of OD compared to PD $(P=0.002)$ (ref. ${ }^{2}$ ).

The Medmont machine that we used to perform the visual field examinations works with the PD and OD indexes.

PD statistics are based on spatial correlation and are a measure of the clustering and depth of the defects. They are a scaled mean value of the product of a point's hill of vision (HoV) deviation and that of its neighbours. They are qualified by the extent to which the deviations are spatially correlated or clustered. For example, if deviations from the patient's HoV are distributed more or less

Table 2. The observed values in patients without local therapy.

\begin{tabular}{lc}
\hline Patients without therapy & \\
\hline Number of patients & 25 \\
Mean age & $61.8 \pm 10.4$ \\
Lowest & 36 \\
Highest & 74 \\
Mean PD (2013) & $2.18 \pm 0.59$ \\
Mean PD (2018) & $2.83 \pm 1.44$ \\
$P$ & 0.0001 \\
Mean OD (2013) & $3.2 \pm 107$ \\
Mean OD (2018) & $3.61 \pm 1.0$ \\
$P$ & 0.0001 \\
Dependence between CCT & $\mathrm{r}=-0.094 P=0.519$ \\
$\quad$ and progression of PD & $\mathrm{r}=0.1876 \quad P=0.192$ \\
Dependence between CCT & $\mathrm{r}=-0.2 \quad P=0.162$ \\
$\quad$ and progression of OD & $\mathrm{r}=-0.443 \quad P=0.001$ \\
Dependence between PD 2013 $\quad$ and 2018 & \\
Dependence between OD 2013 $\quad$ and 2018 &
\end{tabular}


randomly throughout the field, then the PD will be small. As deviations tend to cluster, the index will increase, particularly in cases where both absolute deviations and clustering are high.

$\mathrm{OD}$ is the mean difference between the age-normal $\mathrm{HoV}$ and the mean deviation or patient-based HoV. This number is negative if the patient's HoV is less than the age-normal HoV. Up to three asterisks are appended to this number as a severity indication.

Since PD more closely describes the depth of defects with their aggregation, we used its values to assess changes in the visual fields also in this study.

The study on the relationship of CCT and progression of changes in the visual field in NTG is scarce in the available literature.

The effect of CCT on progression of HTG was investigated by Mokbel et al. and they found that patients with thinner CCT were likely to develop greater glaucomatous optic nerve and visual field damages than those with a thicker CCT ( ref. $^{11}$ ).

No relationship was found between CCT and visual filed (VF) loss in treated patients with primary open-angle glaucoma or normal-tension glaucoma with asymmetrical CCT. Specifically, the thin eye did not have the more advanced VF loss or more rapid VF progression ${ }^{12}$. We might have received these results because they combined HTG and NTG in one group.

Jonas et al. investigated a relationship between CCT and progression of NTG. They found that CCT correlated significantly $(P<0.001)$ and positively with the area of the neuroretinal rim and negatively with the loss of visual field $^{13}$.

Other conclusions were reached by Lin et al. who revealed using the multivariate regression analysis an association between CCT and visual field defect in eyes with NTG but not in eyes with HTG (ref. ${ }^{14}$ ). Erdem et al. monitored 49 patients with NTG for 7-11 years. They found progression in 25 of them but it had not relation to CCT (ref. ${ }^{15}$ ). Choi et al. found that CCT was a significant factor in predicting the extent of localized RNFL defect at the initial examination of NTG patients ${ }^{16}$.

In our study, we did not assume a relationship between CCT and progression of changes in the visual field in NTG, at least in the early stages. We were prompted to this by other pathogenesis of changes in HTG compared to NTG. We also found no study in the literature comparing only NTG patients treated with prostaglandins or locally untreated.

We excluded the patients with NTG who have been treated with beta-blockers from our group. The reason was the outcome of our study, where we did not find a progression of changes in the visual field over five years ${ }^{4}$.

It is possible that the results of other authors are biased by not distinguishing the effect of treatment on NTG progression.

The results of this study confirmed our assumption. There was no relationship between progression of changes in the visual fields and CCT. We found that with the advancement of changes in the visual field, there is a greater progression of these changes. This is similar to HTG.

\section{CONCLUSION}

We found no relationship between progression of changes in the visual fields and CCT. Untreated patients had progression of changes in the visual field in both PD and OD, unlike those who were treated with prostaglandins and had changes only in PD Progression of visual field changes was greater in patients who had more advanced changes at the time of beginning of follow-up.

The study protocol was approved by the local Ethics Committee and the study was performed in accordance with Good Clinical Practice and the Declaration of Helsinki.

\section{ABBREVIATIONS}

CCT, Central corneal thickness; HoV, Hill of vision; HTG, Hypertensive glaucoma; NTG, Normotensive glaucoma; PD, Pattern defect; OD, Overal defect; VF, Visual field.

Author contributions: JL: literature search and drafted the manuscript. All authors contributed equally to data collection, analysis, interpretation and correction of the final manuscript version.

Conflict of interest statement: The authors state that there are no conflicts of interest regarding the publication of this article.

\section{REFERENCES}

1. Lee $B L$, Bathija R, Weinreb RN. The definition of normal-tension glaucoma. J Glaucoma 1998;7: 366-71.

2. Lestak J, Pitrova S, Nutterova E, Bartosová L. Normotensive glaucoma vs hypertensive glaucoma - summary. Cesk Slov Oftal 2019;75:55-60.

3. Lestak J, Pitrova S, Rozsival P. Comparison of b-Blockers and Prostaglandins Treatments in Primary Open-Angle Glaucoma. J Clin Exp Ophthalmol 2013;4:4.

4. Hofschneider V, Lestak J, Pitrova S, Fus M. Changes in Visual Fields in Normotensive Glaucoma. BJSTR 2019;19(5):14614-8. doi: 10.26717/ BJSTR.2019.19.003364

5. Lešták J, Rozsíval P. The Influence of Corneal Thickness on Progression of Hypertensive Glaucoma. J Clin Exp Ophthalmol 2012;3:8. doi: 10.4172/2155-9570.1000245

6. Lešták J, Pitrová Š, Nutterová E. Centrální tloušt'ka rohovky u normotenzních a hypertenzních glaukomů. Čes. a slov Oftal 2018;74:186-9. (In Czech)

7. Araie M, Yamagami J, Suziki Y. Visual field defects in normal-tension and high-tension glaucoma. Ophthalmology 1993;100:1808-14.

8. Zeiter JH, Shin DH, Juzych MS, Jarvi TS, Spoor TC, Zwas F. Visual field defects in patients with normal-tension glaucoma and patients with high-tension glaucoma. Am J Ophtalmol 1992;114:58-63.

9. Caprioli J, Spaeth GL. Comparison of visual field defects in the lowtension glaucomas with those in the high-tension glaucomas. Amer J Ophthalmol 1984;97:730-7.

10. Thonginnetra O, Greenstein VC, Chu D, Liebmann JM, Ritch R, Hood DC. Normal versus high tension glaucoma: a comparison of functional and structural defects. J Glaucoma 2010;19:151-7.

11. Mokbel TH, Ghanem AA. Correlation of central corneal thickness and optic nerve head topography in patients with primary open-angle glaucoma. Oman J Ophthalmol 2010;3:75-80.

12. Cao KY, Kapasi M, Betchkal JA, Birt CM. Relationship between central corneal thickness and progression of visual field loss in patients with open-angle glaucoma. Can J Ophthalmol 2012;47:155-8. 
13. Jonas JB, Stroux A, Velten I, Juenemann A, Martus P, Budde WM. Central corneal thickness correlated with glaucoma damage and rate of progression. Invest Ophthalmol Vis Sci 2005;46:1269-74.

14. Lin W, Aoyama Y, Kawase K, Yamamoto T. Relationship between central corneal thickness and visual field defect in open-angle glaucoma. Jpn J Ophthalmol 2009;53:477-81.
15. Erdem E, Williams A, Kuchar SD, Waisbourd M, Spaeth GL. Longterm (>8 years) evaluation of progression in patients with lowpressure glaucoma. Eur J Ophthalmol 2015;25:490-5.

16. Choi HJ, Kim DM, Hwang SS. Relationship between central corneal thickness and localized retinal nerve fiber layer defect in normaltension glaucoma. J Glaucoma 2006;15:120-3. 